\title{
Linguistic, Cognitive, and Psycholinguistic Perspectives on Metaphors
}

\author{
Nafilah M. Aloairdhi* \\ Department of English Language and Translation, College of Arabic Language and Social Studies, Qassim University, \\ Qassim, Saudi Arabia \\ Noureddine Kahlaoui \\ Department of English Language and Translation, College of Arabic Language and Social Studies, Qassim University, \\ Qassim, Saudi Arabia
}

\begin{abstract}
Language is full of metaphors by nature. Metaphors have been heavily studied in relation to language. However, less attention has been paid to metaphors in relation to cognition and psycholinguistics. This article begins by looking at the idea of metaphors in a general sense. It then considers three perspectives on metaphors as follows: 1) the linguistics perspective, 2) the cognitive perspective, and 3) the psycholinguistic perspective. The aim is both to understand different perspectives on metaphors and to provide more insights about how cognitive and psycholinguistic developments have contributed to the linguistic study of metaphors. This article adopts a descriptive approach in which the focus will be on the theoretical descriptions and explanations. It is hoped that the insights and recommendations shown at this article may contribute to deep understanding of this topic.
\end{abstract}

Index Terms - cognition, linguistics, metaphors, psycholinguistics

\section{INTRODUCTION}

For decades, one of the most popular concepts in the figurative language literature is the concept of metaphors. Metaphors, thus, are directly related to how people use their languages. It is suggested that language is constructed of dead metaphors (Holcombe, 2015). However, recent cognitive and psycholinguistic developments have revealed that metaphors are not only language-specific devices, but also related to humans' conceptual system. Many researchers and scholars have studied metaphors (e.g., Al-Hajaj, 2013; Citron et al., 2020; Hendricks, 2018; Joue et al., 2020; Mashal, 2013).

The different views and theories regarding metaphors have motivated us to explore them deeply. To this end, this article will try to give more details about linguistic, cognitive, and psycholinguistic metaphors. The aims are twofold: the first is to demonstrate different perspectives on metaphors. The second is to shed more light on how cognitive and psycholinguistic developments have contributed to the linguistic study of metaphors. It is hoped that this article provides some insights for those interested in metaphor study.

\section{Metaphors From a Linguistic PersPeCtive}

\section{A. What Is a Metaphor from a Linguistic Perspective?}

Language can be classified as literal or figurative. The figures of speech that can be used in the figurative language include hyperbole, simile, idiom, irony, indirect requests, rhetorical questions, understatement, and metaphors (Kreuz \& Roberts, 1993). Metaphors are extremely important and frequently used in any language.

In language study, a metaphor can be defined as "the use of language to refer to something other than what it was originally applied to, or what it 'literally' means, in order to suggest some resemblance or make a connection between the two things" (Knowles \& Moon, 2006, p. 3). Based on this definition, Al-Hajaj (2013) assumed that the metaphors of a given language cannot be "divorced and isolated" from that language (p. 84, emphasis in original). In the same vein, she stressed that there are many arguments regarding metaphors. These arguments have their diversity from Aristotle's view that sees metaphors as a "gift of genius and cannot be taught" to Shelley's view that considers language as "vitally metaphorical" (Ricoeur, 1977, p. 92).

\section{B. Why Are Metaphors Important?}

Metaphors are important to languages in two principal ways (Knowles \& Moon, 2006). First, they make languages rich as they are important parts in the process of formation of words and words meaning. Second, metaphors are vital

\footnotetext{
* Corresponding author 
and basic components in the discourse as they perform "explaining, clarifying, describing, expressing, evaluating, entertaining" functions (p. 4).

\section{How Are Metaphors Working from a Linguistic Perspective?}

In language, metaphors are considered to work in a specific way. Linguists have different considerations to these ways. For example, Black (1982) considered metaphors as constituted of two elements. One is the frame which represents the context of the metaphor, and the focus which represents the word that is used metaphorically. Another view that considers metaphors in two elements is that of Beekman and Callow (Newmark, 2001). They considered metaphors as the topic that represents the item that has been described by the metaphor, and the similar point between the topic and the word that was used metaphorically.

There is another view that considers metaphors in three elements. Linguistic metaphors, either novel or conventional, are characterised in Richards' terms of tenor (or more recently topic) and vehicle (Avis, 1999). In this sense, tenor represents the conceptual meaning, while vehicle represents the concrete comparison (Al-Hajaj, 2013). However, Avis (1999) has some concerns regarding this division. He preferred discussing linguistic metaphors as "occasions" of metaphors and viewing these occasions through "images". In this way, both occasion and image will "comprise the total event of metaphor" (p. 83).

Newmark (2001) characterised metaphors by five elements. First, the object by which the metaphor will be described. Second, the image which is the element "in terms of which the object is described" (p. 85). Third, the sense which represents the Richards' tenor or Beekman and Callow's similar point. Fourth, the metaphor which is the word understood from the image. Finally, the metonym which is a "one-word image which replaces the object, which may later become a dead metaphor" (p. 85).

\section{What Are the Types of Metaphors?}

There are many different types of metaphors. Generally speaking, metaphors can be classified in three kinds (Yaseen, 2013). First, metaphors are classified according to the verbs in which they are represented. This category, according to Yaseen (2013), contains concretizing, animating, synaesthetic, and personifying metaphors. Concretizing metaphors can express qualities by using abstract items. Animating metaphors are used to add sense to nature. Synaesthetic metaphors are "the transmission of senses" (p. 58). Finally, the personifying metaphors which are used to describe what is not human as human.

The second category of metaphors divides them in terms of their circulation and usage (Yaseen, 2013). This category includes absolute, active, cliché, complex, compound, dead, dormant, extended, implicit, mixed, original, recent, and root metaphors. Table 1 represents these types with their definitions.

The third category to classify metaphors is based on the concepts of the speech of people's experience (Yaseen, 2013). Therefore, this category can be called conceptual metaphor, Yaseen (2013) asserted.

TABLE 1

TYPES OF METAPHORS WITH THIER DEFINITIONS (BASED ON YASEEN, 2013)

\begin{tabular}{|c|c|}
\hline Type of metaphor & Definition \\
\hline 1. Absolute metaphors & $\begin{array}{l}\text { These metaphors are used when there is no obvious similarity } \\
\text { between two items. }\end{array}$ \\
\hline 2. $\quad$ Active metaphors & $\begin{array}{l}\text { These metaphors are not considered as parts of everyday } \\
\text { language. }\end{array}$ \\
\hline 3. Cliché metaphors & $\begin{array}{l}\text { These metaphors are those that have become idioms and } \\
\text { proverbs. }\end{array}$ \\
\hline Complex metaphors & These metaphors "blend uniform over another" (p. 61). \\
\hline 6. $\quad$ Dead metaphors & $\begin{array}{l}\text { "Originally, they are words that used as metaphors, then their } \\
\text { literal meaning had } \\
\text { disappeared and integrated into the language and lost all its } \\
\text { technical features" (p. 61). }\end{array}$ \\
\hline 7. Dormant metaphors & $\begin{array}{l}\text { These metaphors can be considered as in the middle between } \\
\text { live and dead metaphors as the relationship between them and } \\
\text { the original idea they express has been lost. }\end{array}$ \\
\hline 9. Implicit metaphors & $\begin{array}{l}\text { These metaphors have "borrowed name to it which is not } \\
\text { authorized, but is understood implicitly" (p. 63). }\end{array}$ \\
\hline 10. Mixed metaphors & $\begin{array}{l}\text { These metaphors can be used when there is a logical } \\
\text { relationship between two or more metaphors. }\end{array}$ \\
\hline 11. Original metaphors & These metaphors represent poetic and creative metaphors. \\
\hline 12. Recent metaphors & $\begin{array}{l}\text { These are the new and recent metaphors found, for example, in } \\
\text { media. }\end{array}$ \\
\hline 13. Root metaphors & $\begin{array}{l}\text { These are the "metaphors that their roots are extended deeply in } \\
\text { humanitarian thought and their metaphorical concept just } \\
\text { specify the cultural background of the recipient" (p. 64). }\end{array}$ \\
\hline
\end{tabular}




\section{E. What Is beyond Linguistic Metaphors?}

As has been clarified, metaphors are essential to any language. Our languages are full of metaphors. The question that can arise from this fact is that: Are metaphors only linguistic items? It is suggested that in addition to be parts of languages, metaphors are also related to cognitive linguistics and psycholinguistics fields. These details will be shown in the next sections.

\section{Metaphors FROM A COGNITIVE PeRsPeCtive}

\section{A. What Is a Metaphor from a Cognitive Perspective?}

Metaphors can be defined from a cognitive perspective as "understanding one conceptual domain in terms of another conceptual domain" (Kövecses, 2010, p. 4). Kövecses (2010) gave examples of such metaphors as when people talk about life as a journey, arguments as wars, or theories as buildings. He stated that it is convenient to capture this view in terms of conceptual metaphor. Thus, there is a difference between the linguistic expression of a metaphor and the conceptual metaphor.

To distinguish linguistic expression of metaphors from conceptual metaphors, one can think of the former as a way of talking and the latter as a way of thinking (Kövecses, 2010). Therefore, the linguistic expression of metaphors makes the conceptual metaphors explicit. Moreover, the conceptual metaphors that structure humans' thoughts are reflected in a language by the linguistic metaphors (Nacey, 2010). It is worth noting that the notion of conceptual metaphor was firstly introduced by Lakoff and Johnson in 1980 (Kövecses, 2010).

\section{B. How Are Metaphors Working from a Cognitive Perspective?}

As metaphors have specific way to work in the linguistic view of metaphors, they also have a specific way in the cognitive view. Löbner (2002) considered metaphors as items borrowed from one domain (i.e., source domain) to describe other items in another domain (i.e., target domain). Therefore, the metaphorical language can be understood as using things (i.e., items such as notions, concepts, pictures, or models) from the source domain to talk about their similar things in the target domain (Löbner, 2002). Kövecses (2010) suggested that source domain items can be expressed by concrete concepts, while target domain items can be expressed by more abstract concepts.

According to Kövecses (2010), for the relationship between the source and target domains to be understood, it is suggested that there are "systematic correspondences" between them (p. 7). These correspondences represent mappings.

\section{Lakoff and Johnson's Conceptual Metaphor Theory (1980)}

Gilbert (2006) once said:

Giovanni and I have such a good time teaching each other idioms in English and Italian. We were talking the other evening about the phrases one uses when trying to comfort someone who is in distress. I told him that in English we sometimes say, "I've been there." This was unclear to him at first - I've been where? But I explained that deep grief sometimes is almost like a specific location, a coordinate on a map of time. When you are standing in that forest of sorrow, you cannot imagine that you could ever find your way to a better place. But if someone can assure you that they themselves have stood in that place, and have now moved on, sometimes this will bring hope.

_-"So sadness is a place?" Giovanni asked.

—"Sometimes people live there for years," I said. (p. 71, emphasis in original)

What Gilbert has done is explaining what a metaphor is according to the Conceptual Metaphor Theory (Nacey, 2010).

As has been stated, the notion of conceptual metaphor was introduced by Lakoff and Johnson. Al-Hajaj (2013) pointed out that the metaphorical use of a language has been studied by Lakoff and Johnson's Conceptual Metaphor Theory (CMT). In their theory, Lakoff and Johnson contradicted the traditional view of metaphors that considers metaphors as a "matter of words rather than thought or action" (Lakoff \& Johnson, 1980, p. 13). They stressed that metaphors are frequent and common in people daily lives, not only in language use, but also in actions and thoughts. They asserted that the human's conceptual system is metaphorical by nature.

Lakoff and Johnson (1980) provided a complete description of the metaphor: "ARGUMENT IS WAR". Some examples were provided in the analysis representing how one can express "arguments" in terms of "war" (pp. 13-14, emphasis in original), these examples include:

Your claims are indefensible.

He attacked every weak point in my argument.

His criticisms were right on target.

I demolished his argument.

I've never won an argument with him.

You disagree? Okay, shoot!

If you use that strategy, he'll wipe you out.

He shot down all of my arguments.

Al-Hajaj (2013) clarified that CMT goes beyond linguistic level of metaphors to investigate thoughts and cognition. Additionally, it tries to discuss how metaphors are established and formulated. Furthermore, it follows the linguistic 
structuring of metaphors to their launching point that is located in thoughts and cognition. Thus, metaphors "operate on both the linguistic and conceptual levels simultaneously" (Nacey, 2010, p. 10).

1. Types of Conceptual Metaphor

There are three types of conceptual metaphor (Yaseen, 2013). First, structural metaphors which bring an experience in terms of another experience by using particular concepts. Second, orientational metaphors which organise "a whole system of concepts with respect to one another" (Lakoff \& Johnson, 1980, p. 22). Third, ontological metaphors which are used to consider abstract things as concrete ones to make them more tangible to human's mind (Yaseen, 2013).

2. Tenets of Conceptual Metaphor Theory

Conceptual metaphor theory has some basic tenets in how it is related to the language. Lakoff and his colleagues believed that people are aware of many abstract topics such as love and death by metaphors (Deignan, 2005). In this sense, it can be said that metaphors structure thinking (Al-Hajaj, 2013).

Lakoff and Johnson (1980) stressed that "[i]n actuality we feel that no metaphor can ever he [be] comprehended or even adequately represented independently of its experiential basis" (pp. 26-27, emphasis in original). Therefore, metaphors cannot be isolated from experience (Al-Hajaj, 2013). In the same vein, Deignan (2005) pointed out that metaphors are not only beneficial to humans' conceptual system, but also they are important in developing their knowledge. Thus, it can be said that metaphors structure knowledge (Al-Hajaj, 2013).

As has been mentioned, it is observed that metaphors are frequently used in the language. Moreover, metaphors refer in one of their dimensions (or domains) to abstract things. Deignan (2005) justified this frequency as a lack of literal words that can reveal what a metaphor can. He insisted that this is the reason why conceptual metaphor theorists argued that "not only . . . linguistic metaphors are very frequent, but . . . some abstract subjects cannot be talked about without them" (p. 18). Hence, it can be said that metaphors are essential to abstract language (Al-Hajaj, 2013).

\section{Metaphors From a Psycholinguistic PERSPECtive}

Psycholinguistics field studies language and brain. It provides explanations about how language is comprehended and produced, how words are stored and used, and how language is acquired (Field, 2004). However, Field (2004) assured that psycholinguistics is traditionally a challenging area to be studied.

The reason may be attributed to the fact that linguists and psychologists may have different views on language, as "[1]inguists and psychologists talk about different things . . Grammarians are more interested in what could be said than in what people actually say, which irritates psychologists, and psychologists insist on supplementing intuition with objective evidence, which irritates linguists" (Miller, 1990, p. 321). In this section, metaphors from a psycholinguistic perspective will be discussed.

\section{A. How Are Metaphors Working from a Psycholinguistic Perspective?}

1. Bergen's Metaphorical Simulation Hypothesis

It is suggested that metaphors provide a good way to talk about abstract concepts in terms of concrete ones. Bergen (2012) suggested that the abstract concepts may be understood through embodied simulation. In other words, he suggested that people use metaphors to describe an abstract thing in terms of a concrete thing. Thus, it is perhaps that people understand those abstract things in terms of their corresponding concrete ones. He called this proposal Metaphorical Simulation Hypothesis (MSH).

To test MSH, Bergen (2012) started to look at the metaphorical language to identify which concrete things people use to describe abstract ones. Then, he tried to know if people really simulate these metaphors or not. Several experiments have been done to this end.

In one experiment, the participants were required to perform an action (e.g., grasping) just before showing a metaphor that contains the same action applied to an abstract thing (e.g., grasping an idea or concept). The results showed that performing an action that corresponds to the metaphor is helpful in speeding up the comprehension process of that metaphor. Bergen (2012) interpreted this result as the comprehension of the metaphors "activates the motor apparatus responsible for performing the same action" (p. 200).

Later, Bergen (2012) hypothesised that imagining an action would bring the same results as doing it in reality. This hypothesis was tested in the same design as the first one, but instead of asking participants to do an action, they were asked to imagine that they are doing it. The results were consistent with the first study. It was suggested that comprehending metaphors involves embodied simulation of abstract and concrete domains.

In summary, by showing these and other experiments, Bergen (2012) was trying to say that people comprehend metaphorical language depending on embodied simulation of concrete things they use to describe abstract things. Also, he suggested that comprehending a metaphor can be facilitated by the activation of the specific part in the motor system that corresponds to it.

2. Comparisons-Based Theories of Metaphor Processing

Many researchers emphasized that metaphors require a relationship between two domains, and stressed the important role of the context (Nacey, 2010). Thus, it is obvious that the interpretation of figurative and literal meanings is determined by both their context and individual linguistic elements. 
Littlemore and Low (2006) assumed that when a metaphor is involved, then the relationship between the two domains of that metaphor is comprehended through a comparison between some features of the source domain and some other features of the target domain. Therefore, comparison-based theories suggested that "when processing a nominal metaphor . . ., we align the properties of the target term . . . with those of the base term . . and look for an overlap" (Gokcesu, 2009, p. 567).

3. Categorization-Based Theories of Metaphor Processing

As many researchers believed that metaphors are processed based on making comparisons, many other researchers believed that metaphors are better discussed in terms of categorization. One popular model that accounts for this view is Glucksberg and Keyser's Class-Inclusion Model (Glucksberg \& Keysar, 1990).

Class-Inclusion Model supposes that there is a superordinate category that consists of shared attributes by the source and target domains (Glucksberg \& Keysar, 1990). People create this category that encompasses both the term of the source domain and the term of the target domain with one as a more prototypical member (Gokcesu, 2009). Therefore, Glucksberg and Keysar preferred viewing metaphors as "understood by a process of ad-hoc categorization" (Steen, 2007, p. 53).

4. Bowdle and Gentner's Career of Metaphor Theory

Bowdle and Gentner (2005) integrated the two controversial views of processing metaphors (i.e., comparison and categorization) into one theory. They maintained that metaphor processing can be related to either comparison or categorization. They claimed that novel metaphors are processed by comparison, while more conventional metaphors are processed by categorization. They asserted that the interpretation of novel metaphors "involves sense creation", while the interpretation of conventional metaphors "involves sense retrieval" (p. 231). Hence, they considered the level of conventionality as a base to comparison or categorization to be involved (Nacey, 2010).

\section{B. Metaphors and Brain}

As has been stated in this article, metaphors are not only related to the language, but also to human's thoughts and cognition. Recent brain studies have investigated a lot about many claims related to metaphors and brain.

1. Lakoff's Neural Theory of Metaphor

One major development has happened in the study of conceptual metaphors is Lakoff and Johnson's Conceptual Metaphor Theory in 1980. Recently with the development of brain and neural sciences, Lakoff and Feldman have built their Neural Theory of Language (NTL) (Kövecses, 2010). This theory includes Lakoff's Neural Theory of Metaphor (NTM) (Lakoff, 2008). Lakoff continued to consider metaphors as going beyond their linguistic level to the mind, body, and brain (Kövecses, 2010).

Kövecses (2010) provided a thorough description to the Neural Theory of Metaphor. First, he started with the more general theory of language. Basically, a human's brain is made of neurons. In NTL, there are neuronal groups that are patterned as nodes. Every neuron is able to function in various neuronal groups. In this sense, scientists consider semantics as a simulation. Consequently, they attribute the basic role to the mirror neurons. These mirror neurons will fire when one is performing an action or imagining performing that action.

Thus, in this view, the meaning of concrete concepts is considered to be mentally simulated. In other words, one will activate specific neurons that will be required to imagine or perform an action. If a node's activation activates the entire neural simulation, then it can be said that this node is meaningful.

Thoughts happen when two neuronal groups fire simultaneously and their "activation spreads outward along the network links connecting them" (p. 87). While learning, this activation will be strengthened. When this activation from the first neuronal group meets the activation of the second one, a link between them will be made. This link can be stronger the more both neuronal groups fire simultaneously. By this, several kinds of neural circuits will emerge.

As Kövecses (2010) mentioned, there will be different types of neural circuits. One type is linking circuits. This type is responsible for metonymy. Another type is two-way linking circuits, which is responsible for grammatical constructions and vocabulary. However, the type that is important in this article is that of metaphor. The type of neural circuits that characterises metaphors is mapping circuits.

According to Kövecses (2010), the mapping circuits contain two groups of nodes related to source and target domains. In addition, they contain several linking nodes that link elements in the source domain to the elements in the target one. Therefore, the mapping circuits that relate the two nodes will establish a metaphor.

However, Kövecses (2010) pointed out that NTM made a number of significant predictions. First, it predicts that the conceptual metaphors that are based on people's experience in the world are easier to be learned and understood than metaphors that are not related to people's experience. Second, it predicts that nodes related to source and target domains are linked by brain circuitry, thus metaphor processing will activate both nodes. In this way, the metaphor processing will be involved in both of them at the same time. This means that metaphor processing will not take longer time than literal language processing. Kövecses (2010) asserted that number of experimental studies have confirmed both of the above predictions.

2. Different Views on Metaphor Processing

There are some other views on how a metaphor is processed. One of them is the direct approach that supposes that the metaphor processing and literal language processing will happen simultaneously (Gerrig, 1989). Another view is the indirect approach that supposes that the access to metaphors is available when speakers or listeners failed to find a 
logical literal meaning to a linguistic utterance (Amanzio et al., 2007). However, more recent studies have suggested that it is the degree of saliency that determines whether the interpretation of a linguistic utterance, whether figurative or literal, is successful (Giora, 2002).

3. What Do Researchers in Psycholinguistics Say about Metaphor Processing?

It seems that psycholinguistic studies have revealed inconclusive results regarding metaphor processing. However, this section will try to review some results about metaphor processing.

In language processing, it is commonly known that the left hemisphere is prominent. However, Diaz and Hogstrom (2011) pointed out that patient, neuroimaging, and behavioural studies have suggested that the right hemisphere can be responsible in figurative language processing. Furthermore, some studies have explained that the context in which a language is involved can "modify language processes and facilitate comprehension" (p. 3586).

Kacinik and Chiarello (2005) have tried to examine cerebral asymmetries in metaphor comprehension. They suggested that processes in both left and right hemispheres could support metaphor comprehension, but they are not done in the same mechanisms. They asserted that their results are inconsistent with the view that right hemisphere is the "preferred substrate" to comprehend metaphors (p. 188).

In another study, Schmidt and his colleagues (2005) have conducted three experiments to identify whether the right hemisphere is involved in the metaphor processing due to metaphoricity or another part of semantic processing. They varied the familiarity of both literal and figurative sentences. They found that the right hemisphere is involved in unfamiliar sentences processing, while the left hemisphere is involved in familiar sentences processing, regardless of the type of the sentences (i.e., literal or figurative).

Amanzio and her colleagues (2007) conducted a study to investigate nonliteral language comprehension in probable Alzheimer's disease patients. The patients were unimpaired in comprehending conventional metaphors, but they may have some problems regarding comprehending novel metaphors. The results suggested that the impairment in patients' verbal reasoning can be related to the comprehension of conventional and novel metaphors. Also, it was suggested that the poor performance of patients in comprehending novel metaphor can be attributed to the executive impairment. Based on their findings, the researchers suggested a role of prefrontal cortex in comprehending novel metaphors.

To summarize, it was tried in this section to provide an insight that psycholinguistic studies have shown mixed results about metaphor processing. However, more studies are needed to help both linguists and psycholinguists to come to clear conclusions.

\section{CONTRIBUtions OF PSycholinguistics to Linguistics in METAPHOR STUDY}

Psycholinguistics can enrich linguistic studies and go much deeper in understanding different phenomena. Psycholinguistics, especially with the recent developments in research methods in brain study, can give us an excellent way to understand how we produce and comprehend our languages. By focusing on psycholinguistics, we may know how every word is processed in our brains. As psycholinguistics has provided a lot to the languages, it also has given good explanations to illustrate how specific language components and devices and figurative language are processed.

This article tried to shed more light on the study of metaphors. Thus, it was observed that linguistics, cognitive sciences, and psycholinguistics contribute to more understanding of metaphors. First, linguistic studies gave the basis, as we need theoretical assumptions to be able to go a step further. Thus, linguistics defined metaphors, categorised them, and clarified how they are working. Cognitive sciences extended this understanding of metaphors as only linguistic devices to say that they are a matter of cognition and thoughts. After that, psycholinguistics tried to explain how metaphors are processed in our brains, how we can understand abstract things in terms of concrete things, what makes these abstract things clear to us, why we use simulations, and many other issues.

It seems that psycholinguistics has contributed to linguistic study of the metaphors. First, we think it opens many windows to all researchers and scholars to start thinking on metaphors in many different ways. They are not used only to communicate or say something, but to do a much deeper thing. By metaphors, humans are able to understand what is life, love, death, happiness, grief, and all these abstract concepts. By metaphors, we are able to share our "abstract" experience with others, as Gilbert's (2006) "I've been there". By these words that constituted a metaphor, she was able to tell someone else that she went through what he is going through, although both do not exactly have an idea of what a grief is, except that it is a place.

Second, as Lakoff and Johnson stated, our languages are metaphorical by nature. Taking this into account, psycholinguistic studies on metaphors provided much not only to metaphors, but also to the entire language. By psycholinguistic studies on, for example, patients, we may guess and observe how they process metaphors. Thus, we may come to more interesting and promising findings about metaphor processing in both patient and healthy people.

Third, it is thought that psycholinguistic studies on language acquisition can provide a lot of insights on metaphor acquisition, comprehension, and production since metaphors are very popular and commonly used in English. It is believed that findings of such studies can give more opportunities, establish new strategies, and develop a new understanding of language acquisition through learning and acquiring metaphors to second or foreign language learners.

Fourth, as metaphors are stressed to be important, and as confirmed by psycholinguistic studies that they are part of our bodily, cognitive, and linguistic experience, it is thought that we have to notice their existence. In other words, as acquiring linguistic, strategic, or pragmatic competence is a sign of success in a foreign language, it seems that 
metaphoric competence is also an important one to acquire. It will not only help foreign learners to learn a language, but also to be parts of the foreign culture. By being competent in using metaphors, learners can share their experience, understand foreign abstract concepts, and know how foreigners think.

Finally, it is thought that one important contribution of psycholinguistic research is that of how metaphors are processed in different subjects. In other words, psycholinguists have studied metaphor processing in patients, healthy people, and different language speakers. By making comparisons, we may come to interesting conclusions about how metaphors are different from culture to culture. Also, we may know how people from different cultures simulate abstract concepts and understand them.

In summary, psycholinguistic research provides much to the linguistic study of metaphor. It helps linguists to see their theoretical assumptions from a different angle.

\section{CONCLUSION}

As metaphors are an integral part of any language, studying and identifying them would be crucial. Metaphors have been studied and discussed from linguistic, cognitive, and psycholinguistic perspectives. It was shown that a metaphor is not only a language-specific item, but also, as Lakoff and Johnson stated, a matter of thoughts. Psycholinguistic research, in its turn, establishes its scientific bases into this area. Yet, it seems that we have a long journey to discover more about metaphors and how they are working.

\section{REFERENCES}

[1] Al-Hajaj, J. F. (2013). Conceptual/cognitive metaphor theory: Some insights into metaphorical conceptual mappings in poetry. Journal of Basra Researches for Human Sciences, 38(4), 83-104. Retrieved in April 27, 2020 from https://www.researchgate.net/publication/335259696.

[2] Amanzio, M., Geminiani, G., Leotta, D., \& Cappa, S. (2007). Metaphor comprehension in Alzheimer's disease: Novelty matters. Brain and Language, 107, 1-10. doi:10.1016/j.bandl.2007.08.003.

[3] Avis, P. (1999). God and the creative imagination: Metaphor, symbol, and myth in religion and theology. London: Routledge.

[4] Bergen, B. K. (2012). Louder than words: The new science of how the mind makes meaning. New York: Basic Books.

[5] Black, M. (1981). Metaphor. In M. Johnson (Ed.), Philosophical perspectives on metaphor (pp. 63-82). Minnesota: University of Minnesota Press.

[6] Bowdle, B. F., \& Gentner, D. (2005). The career of metaphor. Psychological Review, 112(1), 193-216. Retrieved in April 28, 2020 from https://psycnet.apa.org/doi/10.1037/0033-295X.112.1.193.

[7] Citron, F. M., Lee, M., \& Michaelis, N. (2020). Affective and psycholinguistic norms for German conceptual metaphors (COMETA). Behavior Research Methods, 1-17. Retrieved in April 16, 2020 from https://doi.org/10.3758/s13428-019-01300-7.

[8] Deignan, A. (2005). Metaphor and corpus linguistics. Amsterdam: John Benjamins Publishing Company.

[9] Diaz, M. T., \& Hogstrom, L. J. (2011). The influence of context on hemispheric recruitment during metaphor processing. Journal of Cognitive Neuroscience, 23(11), 3586-3597. doi:10.1162/jocn_a_00053.

[10] Field, J. (2004). Psycholinguistics: The key concepts. New York: Routledge.

[11] Gerrig, R. J. (1989). Empirical constraints on computational theories of metaphor: Comments on Indurkhya. Cognitive Science, 13, 235-241. doi: 10.1016/0364-0213(89)90005-0.

[12] Gilbert, E. (2006). Eat, pray, love: One woman's search for everything across Italy, India, and Indonesia. New York: Penguin Books.

[13] Giora, R. (2002). Literal vs. figurative language: Different or equal? Journal of Pragmatics, 34(4), 487-506. doi: 10.1016/S0378-2166(01)00045-5.

[14] Glucksberg, S., \& Keysar, B. (1990). Understanding metaphorical comparisons: Beyond similarity. Psychological Review, 97(1), 3-18. Retrieved in April 28, 2020 from https://psycnet.apa.org/doi/10.1037/0033-295X.97.1.3.

[15] Gokcesu, B. S. (2009). Comparison, categorization, and metaphor comprehension. Semantic Scholar. Retrieved in April 28, 2020 from https://pdfs.semanticscholar.org/7d79/b585dc326f6f6d2ba8aec25cfaf975148736.pdf.

[16] Hendricks, R. K., Bergen, B. K., \& Marghetis, T. (2018). Do metaphors move from mind to mouth? Evidence from a new system of linguistic metaphors for time. Cognitive Science, 42, 2950-2975. doi: 10.1111/cogs.12693.

[17] Hilpert, M. (2015, February 26). A course in cognitive linguistics: Metaphor [Video]. YouTube. Retrieved in April 20, 2020 from https://www.youtube.com/watch?v=R0BYLpwSM6E.

[18] Holcombe, J. (2015). Metaphor: Theories. Retrieved in April 24, 2020 from http://www.textetc.com/theory/metaphor.html

[19] Joue, G., Boven, L., Willmes, K., Evola, V., Demenescu, L. R., Hassemer, J., Habel, U. (2020). Metaphor processing is supramodal semantic processing: The role of the bilateral lateral temporal regions in multimodal communication. Brain and Language, 205, 1-16. doi: 10.1016/j.bandl.2020.104772.

[20] Kacinik, N. A., \& Chiarello, C. (2005). Understanding metaphors: Is the right hemisphere uniquely involved? Brain and Language, 100, 188-207.

[21] Knowles, M., \& Moon, R. (2006). Introducing Metaphor. London: Routledge.

[22] Kreuz, R. J., \& Roberts, R. M. (1993). The empirical study of figurative language in literature. Poetics, 22(1-2), 151-169. doi: $10.1016 / 0304-422 X(93) 90026-D$.

[23] Kövecses, Z. (2010). Metaphor: A practical introduction (2nd ed.). New York: Oxford University Press.

[24] Lakoff, G. (2008). The neural theory of metaphor. In R. W. Gibbs, Jr. (Ed.), The Cambridge handbook of metaphor and thought (p. 17-38). Cambridge: Cambridge University Press.

[25] Lakoff, G., \& Johnson, M. (1980). Metaphors we live by. Chicago: The University of Chicago Press.

[26] Littlemore, J., \& Low, G. (2006). Figurative thinking and foreign language learning. New York: Palgrave Macmillan. 
[27] Löbner, S. (2002). Understanding semantics. London: Routledge.

[28] Mashal, N., Vishne, T., Laor, N., \& Titone, D. (2013). Enhanced left frontal involvement during novel metaphor comprehension in schizophrenia: Evidence from functional neuroimaging. Brain \& Language, 124, 66-74. doi: 10.1016/j.bandl.2012.11.012.

[29] Miller, G. A. (1990). Linguists, psychologists, and the cognitive sciences. Language, 66(2), 317-322. Retrieved in April 27, 2020 from https://www.jstor.org/stable/414889.

[30] Nacey, S. (2010). Comparing linguistic metaphors in L1 and L2 English [Unpublished doctoral dissertation]. Oslo: University of Oslo.

[31] Newmark, P. (2001). Approaches to translation. New York: Pergamon Press.

[32] Ricoeur, P. (1977). The rule of metaphor: The creation of meaning in language. London: Routledge.

[33] Schmidt, G. L., DeBuse, C. J., \& Seger, C. A. (2005). Right hemisphere metaphor processing? Characterizing the lateralization of semantic processes. Brain and Language, 100, 127-141. doi: 10.1016/j.bandl.2005.03.002.

[34] Steen, G. J. (2007). Finding metaphor in grammar and usage: A methodological analysis of theory and research. Amsterdam: John Benjamins Publishing Company.

[35] Yaseen, A. H. (2013). The commonest types of metaphor in English. Journal of Al-Frahedis Arts, 3(15), 52-69. Retrieved in April 25, 2020 from https://www.iasj.net/iasj?func=fulltext\&aId=84981.

Nafilah M. Aloairdhi is an MA student in applied linguistics program at Qassim University, Saudi Arabia. She received a bachelor's degree in English language and translation from Qassim University.

Noureddine Kahlaoui is Assistant Professor of linguistics at Qassim University. He received his Ph.D. from the University of Montreal. 